\title{
Evolução da participação feminina e masculina em afazeres domésticos no Brasil
}

\author{
Evolution of female and male participation in domestic chores in Brazil
}

Marcos Vinicius Dalagostini Bidarte ${ }^{1}$ Carolina Freddo Fleck ${ }^{2}$

\section{Resumo}

Esta pesquisa apresenta uma análise da evolução da participação feminina e masculina na realização de afazeres domésticos no Brasil, considerando os dados publicados pela Pesquisa Nacional por Amostra de Domicílios (PNAD) para o período 20042014. Os resultados revelam que o número médio de horas semanais gastas na realização de afazeres domésticos está crescendo apenas para os homens residentes nas Regiões Norte (1,6\% a.a.) e Sul ( $1 \%$ a.a.); em relação às mulheres, apenas para as residentes na Região Norte (1,3\% a.a.). Constatou-se que a participação masculina na realização de afazeres domésticos no Brasil cresceu, em média, $11 \%$ no período 2004-2014, enquanto a feminina mostrou-se constante. No entanto, ainda se perpetua a desigualdade de gênero no país com relação à distribuição do tempo dedicado à realização de afazeres domésticos.

Palavras-chave: Gênero; Trabalho reprodutivo; Distribuição do tempo.

\begin{abstract}
This research analyses the evolution of female and male participation in household tasks in Brazil, using the data released from the Pesquisa Nacional por Amostra de Domicílios (PNAD - National Household Sample Survey) for the period 2004-2014. The results indicate that the average weekly hours spent in domestic tasks is increasing only for men living in the macro-regions North (1.6\% a.a.) and South (1\% a.a.); and to women, only in the macro-region North $1.3 \%$ a.a.). The study shows that male participation in domestic tasks in Brazil grew by an average of $11 \%$ during the period, while that of women stayed constant. Despite that, gender inequality perpetuates in the country related to the distribution of time spent in domestic tasks.
\end{abstract}

Key-words: Gender. Domestic Labor. Distribution of Time.

\footnotetext{
${ }^{1}$ Mestre em Administração pela Universidade Federal do Pampa. Professor substituto na Universidade Federal do Rio Grande. E-mail: viniciusbidarte@hotmail.com

2 Doutora em Administração pela Universidade Federal do Rio Grande do Sul. Professora Adjunta na Universidade Federal do Pampa. E-mail: carolinafleck@unipampa.edu.br
} 


\section{INTRODUÇÃO}

A divisão de papéis entre homens e mulheres na sociedade parece normatizada desde que o mundo é mundo. Vive-se em uma espécie de "discurso naturalista, que insiste na existência de duas 'espécies' com qualidades e aptidões particulares. Aos homens, o cérebro (...), a capacidade de decisão. Às mulheres, o coração, a sensibilidade, os sentimentos" (PERROT, 1988, p. 177). Aos homens, o público; às mulheres, o privado. Aos homens, a rua; às mulheres, a casa.

Por haver nas mulheres tendência ao sentimentalismo, não lhes era atribuído o valor para ocupar espaço na esfera pública. Desse modo, as mulheres ficaram responsáveis pelas tarefas domésticas e pelos cuidados com a família. Aos homens, por outro lado, era fundamental que ocupassem os espaços na esfera pública, por serem mais reflexivos e perspicazes para liderança, visto que deveriam ser os responsáveis pelo provimento financeiro da família e desenvolvimento da sociedade (PERROT, 1988).

O fato é que a situação da sociedade permaneceu assim até meados das décadas de 1960 e 1970, quando as mulheres começaram a lutar mais por seus direitos, por seu "espaço na rua" e buscaram posicionamento no mercado de trabalho. Efetivamente, ganharam espaço, mas também acumularam funções. A sociedade "entendeu" que a mulher poderia ingressar no mercado de trabalho, mas ainda cabiam a ela as atribuições da casa e da família. Apesar dos avanços sociais, essas mulheres mantiveram as demandas de casa sob sua responsabilidade, o que mais tarde veio a ser caracterizado pelos/as estudiosos/as feministas como dupla jornada de trabalho (BRUSCHINI, 1985, 1994; SORJ, 2005).

No Brasil, a década de 1970 foi marcada pela proclamação da Década da Mulher pela Organização das Nações Unidas e pelo início do movimento feminista (REPORT..., 1976), fortalecendo a busca pela liberdade e igualdade entre os sexos e permitindo o ingresso de um número maior de mulheres no mercado de trabalho. Mulheres que passaram a contribuir com a sociedade duplamente, encarando um mercado de trabalho hostil, por conta do machismo que predominava, e desdobrando-se nos diversos papéis de dona de casa, mãe, esposa etc.

No entanto, a grande conquista das mulheres ficou mascarada nas estatísticas. Os dados sobre esse período não correspondem efetivamente à realidade e não dão parâmetro real do que acontecia à época. Entre as décadas de 1970 e 1980, as estatísticas oficiais do Brasil foram criticadas por serem consideradas inadequadas, pois os conceitos e procedimentos metodológicos utilizados para mensurar o trabalho doméstico não mostravam a real contribuição feminina à sociedade brasileira. Exigia-se, portanto, que as informações sobre os afazeres 
domésticos fossem divulgadas à sociedade de forma aberta, não permanecendo apenas em poder dos responsáveis pelas pesquisas oficiais nacionais (BRUSCHINI, 2006, 2007).

Ao que parece, não havia necessidade de analisar esses dados e levá-los ao conhecimento público, uma vez que os afazeres domésticos nada mais eram do que uma obrigação das mulheres. Permanecia a noção de uma atividade como "não atividade" na prática. Não era contabilizada como tempo de trabalho, nem de não trabalho. Pode-se imaginar os afazeres domésticos como algo que simplesmente acontecia, quase como "mágica". A sociedade ainda precisava de tempo para assimilar mais essa mudança e entender que os afazeres domésticos também devem ser considerados como trabalho.

Foram necessárias duas décadas para que isso começasse a acontecer, e os dados sobre os afazeres domésticos passassem a ser coletados e então divulgados à sociedade brasileira. Em 1992, os afazeres domésticos começaram a fazer parte do tópico "Trabalho e Rendimento" da Pesquisa Nacional por Amostra de Domicílios (PNAD), planejada e executada pelo Instituto Brasileiro de Geografia e Estatística (IBGE) (PNAD, 1992). Contudo, foi somente após a realização da IV Conferência Mundial sobre a Mulher, em Pequim, China, que a PNAD iniciou, em 2001, a investigação do número de horas semanal médio gasto pelos respondentes na realização de afazeres domésticos no Brasil (PNAD, 2001).

A partir de então, surgiram diversas pesquisas nacionais analisando a divisão sexual dos afazeres domésticos e mostrando a desigualdade de gênero em relação à realização de afazeres domésticos (BRUSCHINI, 2007; SORJ, 2004). Com o passar das décadas e especialmente nos últimos anos (década de 2010), mudanças sociais importantes ocorreram, como o fato de que é cada vez maior o número de mulheres no mercado de trabalho e com maior nível educacional (IBGE, 2014), e de que os homens começaram a perceber que a cultura masculinizada, que sempre predominou, deve ser extinta para que um universo de igualdade entre os sexos seja criado. Essas mudanças substanciais repercutiram sobre a distribuição do tempo das pessoas, fazendo com que os homens participassem mais da realização de afazeres domésticos (BRUSCHINI, 2007; BRUSCHINI; RICOLDI, 2012), e que diminuísse a percepção enraizada da sociedade de que as responsáveis pela realização dos afazeres domésticos são, via de regra, as mulheres (MELO; SABBATO, 2011).

Entretanto, será que, efetivamente, as coisas estão mudando? Diante dos argumentos apresentados, a presente pesquisa tem como objetivo apresentar uma análise da evolução temporal da participação feminina e masculina na realização de afazeres domésticos, segundo as regiões do Brasil e em nível nacional, no período 2004-2014. Um intervalo que marca a segunda metade de uma década e a primeira metade de outra, justamente em um momento em 
que a sociedade reflete sobre a necessidade de mudanças e o entendimento dos papéis sociais dos indivíduos, intensificando a necessidade de igualdade entre os sexos e diminuição do preconceito de gênero nas diversas esferas da vida. Desse modo, a presente pesquisa busca contribuir, por meio de objetivos complementares, com reflexões sobre as (des)igualdades na realização de afazeres domésticos entre os sexos no país, bem como sobre o uso do tempo pelos homens e pelas mulheres, e as implicações que esse traz para a questão de gênero. Quanto à estrutura desta pesquisa, apresenta-se primeiramente o debate teórico sobre a mensuração e visibilidade dos afazeres domésticos no Brasil. Após esta contextualização, apresentam-se, de modo aplicado, os procedimentos metodológicos utilizados na condução desta pesquisa. Por fim, apresentam-se as seções de análise dos dados e a discussão dos resultados e as considerações finais com sugestões de pesquisas futuras na área.

\section{AFAZERES DOMÉSTICOS: MENSURAÇÃO E VISIBILIDADE DO TRABALHO DOMÉSTICO NÃO REMUNERADO NO BRASIL}

No Brasil, os afazeres domésticos começaram a ser investigados e divulgados à sociedade brasileira pela PNAD somente em 1992, em um tópico amplo e específico denominado "Trabalho e Rendimento". Essa informação passou a ser coletada por meio da questão de número 121 do questionário da PNAD de 1992, à qual se limitava apenas a perguntar se na semana de 20 a 26 de setembro de 1992 o/a respondente havia cuidado dos afazeres domésticos em sua residência (PNAD, 1992). De fato, consistia em uma informação incipiente, mas permitia um mapeamento inicial sobre quem (mais) se envolvia com as tarefas domésticas.

Três anos depois, em 1995, a Organização das Nações Unidas promoveu a IV Conferência Mundial sobre a Mulher, em Pequim, China, e publicou, posteriormente, um documento intitulado "Declaração e Plataforma de Ação de Pequim" contendo 12 pontos prioritários de trabalho objetivando a igualdade de gênero e a eliminação da discriminação contra mulheres e meninas no mundo todo. Especificamente sobre o ponto "Mulher e Economia", o documento listou, como objetivo estratégico de elaboração e divulgação de dados e informações desagregados por gênero, para fins de planejamento e avaliação pelos Estados, conforme pode ser visto nos seguintes itens:

g) desenvolver uma classificação internacional de atividades, para a elaboração de estatísticas baseadas no emprego de tempo, sensíveis às diferenças entre o homem e a mulher no tocante a trabalho remunerado e não remunerado, e coletar dados discriminados por sexo em nível nacional, sujeito às restrições nacionais:

i - empreender estudos periódicos sobre o emprego do tempo para medir quantitativamente o trabalho não remunerado, registrando inclusive as atividades que se 
realizam simultaneamente com as atividades remuneradas ou outras atividades não remuneradas;

ii - medir quantitativamente o trabalho não remunerado que não é incluído nas contas nacionais e buscar melhorar os métodos de aferição do seu valor, para que este seja indicado com exatidão em contas especiais ou outras contas oficiais preparadas separadamente das contas nacionais básicas, mas em consonância com estas (DECLARAÇÃO..., 1995, p. 222).

A Declaração e Plataforma de Ação de Pequim recomendou que o trabalho não remunerado, realizado majoritariamente pelas mulheres, seja incorporado em um sistema de contas-satélites, objetivando dar visibilidade aos indivíduos e aos afazeres domésticos (DECLARAÇÃO..., 1995). A partir da publicação do documento supramencionado, houve uma proliferação de estudos sobre o emprego do tempo medindo o trabalho não remunerado em todo o mundo (MELO; CASTILHO, 2009).

Apesar da recomendação do documento supramencionado e dos estudos que surgiram posteriormente, apenas em 2001 o Brasil avançou com a PNAD ao inserir a questão complementar de número 121-a em seu questionário, sendo aplicada àqueles respondentes que disseram "sim" à questão anterior. Dessa forma, a referida pesquisa passou a investigar o número de horas semanal médio gasto pelos respondentes, total e ocupados, na realização de afazeres domésticos por regiões, unidades da federação e regiões metropolitanas do Brasil e em nível nacional, e ainda os classificou por sexo e faixa etária (PNAD, 2010). Essa questão constituiu importante marco de investigação, pois possibilitou cruzamentos de dados e, como reflexo, o desenvolvimento de séries históricas.

Após anos de pesquisas sobre se as pessoas habitualmente cuidavam, parcial ou integralmente, da realização dos afazeres domésticos e o número de horas semanal médio gasto pelas mesmas, a PNAD definiu como afazeres domésticos a realização, no domicílio e residência, de tarefas como: arrumar ou limpar toda ou parte da moradia; cozinhar ou preparar alimentos, passar roupa, lavar roupa ou louça, utilizando, ou não, aparelhos eletrodomésticos para executar essas tarefas para si ou para outro(s) morador(es); orientar ou dirigir trabalhadores domésticos na execução das tarefas domésticas; cuidar de filhos ou menores moradores; ou limpar o quintal ou terreno que circunda a residência (PNAD, 2008, p. 34).

A definição da categoria "afazeres domésticos" pela PNAD foi questionada por Bruschini (2007) justamente por englobar um conjunto de tarefas diversificadas, as quais não são corretamente detalhadas nos levantamentos oficiais do Brasil, o que, segundo Melo e Castilho (2009), contribui para que não seja possível saber exatamente o que é o trabalho doméstico. Ainda, Cristiane Soares e Ana Sabóia (2007) criticaram o conceito de afazeres domésticos utilizado pela PNAD, mostrando que o mesmo é amplo e genérico, mas permite analisar de forma aproximada o uso do tempo pelos brasileiros, total e ocupados. No entanto, os dados disponíveis 
sobre os afazeres domésticos e o número médio de horas semanal gasto pelos indivíduos na execução desses são muito recentes e escassos, como bem sinalizado por Madalozzo, Martins e Shiratori (2010).

De acordo com os dados do IBGE, a média de horas semanais gastas em afazeres domésticos, por pessoas de 16 anos ou mais, revela que as mulheres gastam 25,3 horas, enquanto os homens apenas 10,9 horas; em relação às pessoas ocupadas, a média de horas semanais gastas em afazeres domésticos pelas mulheres é de 21,2 horas, contra 10,0 horas pelos homens (IBGE, 2014). Duas questões importantes aparecem nesses dados. Primeiro, mesmo que os homens estejam inseridos no contexto das tarefas domésticas, a média de horas semanais gastas em afazeres domésticos pelas mulheres brasileiras é mais que o dobro da média apresentada pelos homens. Segundo, o número de horas semanais gastas em afazeres domésticos pelas mulheres diminui um pouco quando essas estão inseridas no mercado de trabalho, e o dos homens permanece praticamente constante. Isso revela, aparentemente, que se perpetua a noção de que as mulheres, estejam ou não inseridas no mercado de trabalho, são as principais responsáveis pela realização dos afazeres domésticos.

A partir da década de 1990 as mudanças sociais que ocorreram e repercutiram sobre a distribuição do tempo das pessoas fizeram com que as dinâmicas familiares também passassem por transformações, e a principal delas é a de que os homens participam mais do cotidiano familiar e dos cuidados com os filhos, bem como se envolvem mais na realização de afazeres domésticos. Ainda que tímida, a presença masculina na realização de afazeres domésticos não pode ser desprezada (BRUSCHINI, 2007; BRUSCHINI; RICOLDI, 2012), mesmo que os homens demonstrem ser seletivos na realização dos afazeres domésticos, preferindo tarefas que envolvam interseção entre a esfera privada e pública (como realizar compras da casa), tarefas interativas (como cuidar dos filhos), tarefas intelectuais (como ajudar os filhos nos deveres escolares) ou, ainda, tarefas domésticas valorizadas (como culinária sofisticada) (BRUSCHINI, 1990, 2007; SORJ, 2004).

\section{PROCEDIMENTOS METODOLÓGICOS}

Buscando-se analisar a evolução da participação feminina e masculina na realização de afazeres domésticos segundo as regiões do Brasil e em nível nacional, optou-se pelo método levantamento, por estudar fenômenos sociais e relações entre variáveis. Nesse sentido, justificase a escolha da pesquisa de natureza empírica, de abordagem quantitativa e de caráter descritivo (COLLIS; HUSSEY, 2005; CRESWELL, 2007; FLICK, 2009). 
A técnica de coleta de dados escolhida foi a documental, com dados secundários (COLLIS; HUSSEY, 2005), utilizando como fonte de dados os documentos publicados pela PNAD e pelo IBGE referentes à média de horas semanais gastas em afazeres domésticos, das pessoas de 16 anos ou mais de idade, por sexo, segundo as regiões do Brasil e em nível nacional. Verificou-se que os primeiros dados referentes às médias de horas semanais gastas em afazeres domésticos pelos homens e pelas mulheres foram encontrados somente em algumas Sínteses dos Indicadores Sociais publicadas pelo IBGE (2006a, 2006b, 2007, 2008, 2009, 2010, 2012, 2013).

Dessa forma, os dados publicados foram compilados e solicitaram-se às duas agências do IBGE (uma na cidade de residência dos pesquisadores e outra na capital do estado do Rio Grande do Sul) os demais dados, compreendendo uma série histórica para o período 2004-2014. Ressalta-se que em 2010 não houve a PNAD, em razão da realização do Censo Demográfico (IBGE, 2012); portanto, calculou-se a média aritmética para as horas semanais gastas em afazeres domésticos pelas mulheres e pelos homens, segundo as regiões do Brasil e em nível nacional para o referido ano, utilizando os dados de 2009 (IBGE, 2010) e 2011 (IBGE, 2012).

Os dados coletados foram analisados por meio do Teste de Hipótese e da Regressão Semilogarítmica. Primeiramente, foi estimado o Teste $t$-student para duas amostras, unilateral, com um nível de significância de $5 \%(\alpha=0,05)$, visando verificar se há diferença entre as médias das amostras do número de horas semanais gastas na realização de afazeres domésticos pelas mulheres e pelos homens. Nessa etapa da pesquisa, as seguintes hipóteses foram formuladas e testadas:

\footnotetext{
Hipótese Nula $\left(\mathrm{H}_{0}\right): \mu$ HАН $\leq \mu \mathrm{HAM}$

Hipótese alternativa $\left(\mathrm{H}_{1}\right): \mu \mathrm{HAH}>\mu \mathrm{HAM}$
}

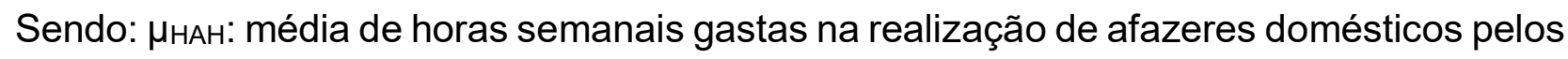
homens; HнM: média de horas semanais gastas na realização de afazeres domésticos pelas mulheres.

Em um segundo momento, utilizou-se a regressão semilogarítmica para mensurar relações lineares existentes entre duas variáveis: "horas semanais gastas com a realização de afazeres domésticos" (variável dependente y) e "tempo" (variável independente x), para o período 2004-2014, pelas mulheres e pelos homens para cada uma das regiões do Brasil e em nível nacional, com um nível de significância de 5\% $(\alpha=0,05)$. Para tanto, utilizou-se o seguinte modelo de regressão semilogarítmica (Equação 1), descrito por Gujarati (2000, p. 529): 


$$
\ln Y_{i}=\alpha+\beta t_{i}+\varepsilon_{i}
$$

Onde: $Y_{i}=$ horas semanais gastas com a realização de afazeres domésticos; $\ln Y_{i}=$ logaritmo natural do tempo semanal gasto com a realização de afazeres domésticos; $\alpha=$ intercepto; $\beta=$ coeficiente angular; $t=$ tempo da série histórica representado pelo número de anos; $\varepsilon=$ erro aleatório

Após coletados e tabulados, os dados foram analisados com auxílio de software estatístico. Os resultados apresentados na sequência vêm a complementar os estudos sobre afazeres domésticos e pretendem contribuir com a análise dos dados dos últimos anos, bem como apresentar indicadores de estudos futuros que possam mapear com mais clareza a questão dos afazeres domésticos entre homens e mulheres no Brasil.

\section{PARTICIPAÇÃO FEMININA E MASCULINA NA REALIZAÇÃO DE AFAZERES DOMÉSTICOS: (DES)IGUALDADE ENTRE OS SEXOS NO BRASIL?}

A análise dos dados revelou que as mulheres, em todas as regiões do Brasil e em nível nacional, apresentam médias de horas semanais gastas em afazeres domésticos maiores do que as dos homens (Tabela 1). Como era esperado, dado que por mais que a sociedade reflita sobre as questões de gênero e já trate com maior naturalidade a ideia de igualdade entre os sexos, estudos como os de Sorj (2004), Bruschini (2007), Soares e Saboia (2007), Soares (2008), Ricoldi (2010), Bruschini e Ricoldi (2012) e Bidarte (2018) e as pesquisas do IBGE $(2010,2014)$ demonstram que a desigualdade persiste, e as mulheres seguem possuindo a maior carga de trabalho doméstico, em comparação aos homens. Mas, se a desigualdade persiste, qual a contribuição desta pesquisa? Os dados a seguir demonstram que existe modificação no cenário dos afazeres domésticos, e esses dados podem ser indicadores de uma análise futura sobre a questão dos afazeres domésticos por outras perspectivas, que não apenas as questões de desigualdade de gênero.

Considerando apenas o número de horas semanais médio dedicado aos afazeres domésticos, pelos homens $(10,482)$ e especialmente pelas mulheres $(25,655$ horas) brasileiras, de acordo com Bruschini (2006, p. 331), "seria legítimo considerar esta categoria um trabalho não remunerado e não mais inatividade econômica" nas pesquisas nacionais oficiais. Os afazeres domésticos consomem parte considerável do tempo dos indivíduos que os realizam e, 
por vezes, consomem um tempo que poderia ser dedicado a outras atividades, sejam elas produtivas, no mercado de trabalho; de lazer; descanso; estudos; dentre outras. Os dados desta pesquisa corroboram a afirmação de Bruschini, e os autores reforçam o coro de que é mais do que necessário que se considerem os afazeres domésticos como um trabalho não remunerado e que este passe a compor as análises estatísticas referentes a mercado de trabalho e desenvolvimento econômico.

Tabela 1 - Médias e Valores do Teste T para as amostras do tempo semanal gasto com a realização de afazeres domésticos, pelas mulheres e pelos homens, segundo as regiões do

Brasil e em nível nacional, no período 2004-2014

\begin{tabular}{c|c|c|c|c}
\hline \multirow{2}{*}{ Região } & \multicolumn{2}{|c|}{ Média } & T $_{\text {calculado }}$ & Valor-p \\
\cline { 2 - 5 } & Mulheres & Homens & & \\
\hline Norte & 23,936 & 10,482 & $-27,748$ & 0,000 \\
\hline Nordeste & 27,473 & 10,900 & $-34,596$ & 0,000 \\
\hline Centro-Oeste & 23,900 & 9,991 & $-39,631$ & 0,000 \\
\hline Sudeste & 25,582 & 10,573 & $-44,527$ & 0,000 \\
\hline Sul & 24,236 & 9,918 & $-37,825$ & 0,000 \\
\hline Brasil & 25,655 & 10,482 & $-41,814$ & 0,000 \\
\hline
\end{tabular}

Fonte: Elaborado pelos autores

Nota: Valor do $\mathrm{T}_{\text {tabelado }}=-1,725$

Considerando os dados apresentados na Tabela 1, verificou-se que as mulheres residentes na Região Nordeste são as que mais dedicam horas semanais para a realização de afazeres domésticos (27,473 horas), enquanto as mulheres residentes na Região Centro-Oeste são as que dedicam menos horas para a realização desses mesmos afazeres (23,9 horas). Do mesmo modo, verificou-se que a média de horas semanais gastas em afazeres domésticos pelos homens é maior para os residentes na Região Nordeste (10,9 horas) e menor para os residentes na Região Sul (9,918 horas). Os dados demonstram desequilíbrio entre as regiões do país, não havendo indicativo de que entre elas poderia haver uma percepção diferente no que diz respeito à realização dos afazeres domésticos; por exemplo, onde impactariam questões culturais e de desenvolvimento, dado o tamanho continental do Brasil e as diferenças características entre as regiões. No entanto, não deve ser descartada a possibilidade de um estudo aprofundado entre as regiões brasileiras, procurando mapear as características da população de cada uma delas, no que diz respeito à distribuição dos afazeres domésticos entre os sexos.

Nota-se que a Região Nordeste apresentou maior média de horas semanais gastas em afazeres domésticos tanto para os homens quanto para as mulheres, comparada com as demais regiões brasileiras. É interessante destacar que a referida região ocupa o segundo lugar na proporção de casais com filhos e o quarto lugar na proporção de casais sem filhos no país. O 
percentual de arranjos familiares compostos por casais com filhos nessa região passou de $52 \%$ para 44,9\% no período de 2004 a 2013 - queda de 13,7\%; já o percentual de arranjos familiares compostos por casais sem filhos passou de $12,9 \%$ para $17,7 \%$ no mesmo período - aumento de $37,5 \%$. Um fator explicativo para a maior proporção de casais com filhos é a presença de taxas de fecundidade mais elevadas na Região Nordeste do que nas demais regiões do Brasil (IBGE, 2014). O fato de ser a região com mais filhos poderia ajudar a explicar o porquê de se gastar mais tempo nos afazeres domésticos, uma vez que a PNAD indica que uma das tarefas que envolve o conceito de afazeres domésticos é o de cuidado com os filhos.

Além disso, dadas algumas características socioeconômicas da Região Nordeste do país, caberia uma investigação com novos dados, para verificar se a razão do dobro da média de horas semanais gastas em afazeres domésticos pelas mulheres nordestinas, em relação aos homens nordestinos, pode ser devido à maior oferta de postos de trabalhos informais e precários e por apresentar baixa formalização no mercado de trabalho; à menor oferta de trabalhadores domésticos e ao aumento real de seus rendimentos, que acaba dificultando a contratação de tais serviços; à persistente desigualdade de rendimentos médios entre homens e mulheres (IBGE, 2012); ao arranjo familiar composto por casal com filhos, chefiado por homem, em que a responsabilidade pela realização dos afazeres domésticos recai sobre a mulher (IBGE, 2014); e à ausência de aparelhos eletrodomésticos e acesso a novas tecnologias nos domicílios, reflexo dos baixos rendimentos mensais (IBGE, 2015; SOARES; SABÓIA, 2007), dentre outros fatores.

De modo geral, percebe-se que em todas as regiões do Brasil e em nível nacional há disparidade de horas semanais gastas na realização de afazeres domésticos entre os sexos. Isso é um reflexo da cultura que se desenvolveu, não apenas no Brasil, mas em todo o mundo, de que a divisão dos afazeres domésticos não é equânime entre homens e mulheres, e que recai às mulheres a responsabilidade pela realização da maior parte do trabalho reprodutivo ${ }^{3}$, bem como pelos cuidados dos filhos e demais familiares, quando houver. No entanto, o fato de os homens figurarem com registro de horas semanais vinculadas a afazeres domésticos demonstra que a realidade vem sendo modificada, ainda que lentamente.

As mulheres que se inserem no mercado de trabalho (formal ou informal) geralmente continuam sendo as responsáveis pela realização dos afazeres domésticos, caracterizando a denominada "dupla jornada de trabalho" (IBGE, 2014, 2015). A título de informação, em 2014 a proporção de mulheres brasileiras realizando a dupla jornada de trabalho era de $88 \%$, enquanto entre os homens a proporção era de 46\% (IBGE, 2015). Esses dados revelam que o aumento

\footnotetext{
${ }^{3}$ Refere-se à realização de atividades de apoio e domésticas, como cuidados relativos à família e filhos, na esfera privada (IBGE, 2012).
} 
da participação feminina no mercado de trabalho não necessariamente significa abandonar a realização de afazeres domésticos (SOARES; SABÓIA, 2007), perpetuando que o ideário da mulher como responsável "pela casa" (PERROT, 1988) ainda não foi desconstruído. No entanto, esses percentuais são utilizados pelos/as estudiosos/as como dados importante para a luta pela igualdade de gênero no Brasil.

Essa percepção social é reforçada nos dados apresentados na Tabela 1, pois nitidamente há uma desigualdade de gênero com relação à distribuição do tempo. Uma explicação para isso é a separação de papéis entre homens e mulheres na sociedade, sendo reservada às mulheres a esfera privada, enquanto aos homens a esfera pública (BIDARTE, 2018; BIDARTE; FLECK; MELLO, 2018; BRUSCHINI, 2006; IBGE, 2012; MADALOZZO; MARTINS; SHIRATORI, 2010; MELO; CONSIDERA; SABBATO, 2007; SAFFIOTI, 1987). Quanto maior for o tempo dedicado pelos indivíduos, principalmente pelas mulheres, à realização dos afazeres domésticos, bem como aos cuidados dos filhos e demais familiares, menor é o tempo dedicado ao trabalho produtivo $^{4}$ na esfera pública e profissional (IBGE, 2010), bem como ao acesso a lazer, descanso, estudos, dentre outros.

Considerando todos os pontos que já foram destacados até este momento, cabe a ressalva de que o questionário utilizado pela PNAD ainda é escasso de informações que nos permitam maior aprofundamento no tratamento dos dados, como, por exemplo, conhecer quais afazeres domésticos são realizados pelos homens e pelas mulheres brasileiras no trabalho doméstico, bem como saber se os homens ou as mulheres que assumem os afazeres domésticos o fazem porque dividem as tarefas com sua/seu parceiro/a ou ainda porque moram sozinhos e, neste caso, a responsabilidade recai sobre eles/elas. Nesse sentido, os autores pretendem apresentar no futuro estudos mais detalhados que permitam encontrar tais informações e trazer um mapeamento ainda mais completo sobre a questão da realização e divisão dos afazeres domésticos entre homens e mulheres no Brasil.

Não se pode desconsiderar o fato de que os homens apresentaram dados de uso do tempo na realização de afazeres domésticos, além das mulheres, o que já era esperado. Sendo assim, no intuito de explicar a evolução da média de horas semanais gastas na realização de afazeres domésticos pelas mulheres e pelos homens no período de 2004 a 2014, foi realizada a análise de regressão semilogarítmica para cada uma das regiões do Brasil e em nível nacional (Tabela 2), procurando demonstrar as mudanças que a sociedade brasileira vem apresentando no que diz respeito aos afazeres domésticos.

\footnotetext{
${ }^{4}$ Refere-se à realização de atividades produtivas de bens ou serviços com valor econômico de mercado na esfera pública (IBGE, 2012).
} 
Tabela 2 - Coeficientes da regressão semilogarítmica do tempo semanal gasto com a realização de afazeres domésticos pelas mulheres e pelos homens, segundo as regiões do Brasil e em nível nacional, no período 2004-2014

\begin{tabular}{|c|c|c|c|c|}
\hline Região & $\begin{array}{l}\text { Intercepto } \\
\text { (a) }\end{array}$ & $\begin{array}{l}\text { Coeficiente } \\
\text { Angular }(\beta)\end{array}$ & $\mathbf{T}_{\text {calculado }}$ & $\begin{array}{l}\text { Valor } \\
\text { p-fishel }\end{array}$ \\
\hline $\begin{array}{c}\text { Norte } \\
\text { InY } \text { iMulheres }=\alpha+\beta(t) \\
\ln Y_{\text {iHomens }}=\alpha+\beta(t)\end{array}$ & $\begin{array}{l}3,093 \\
2,250\end{array}$ & $\begin{array}{l}0,013 \\
0,016\end{array}$ & $\begin{array}{l}3,255 \\
4,383\end{array}$ & $\begin{array}{l}0,010 \\
0,002\end{array}$ \\
\hline $\begin{array}{c}\text { Nordeste } \\
\text { InY } Y_{\text {iMulheres }}=\alpha+\beta(t) \\
\ln Y_{\text {iHomens }}=\alpha+\beta(t)\end{array}$ & $\begin{array}{l}3,283 \\
2,338\end{array}$ & $\begin{array}{l}0,005 \\
0,008\end{array}$ & $\begin{array}{l}0,950 \\
0,438\end{array}$ & $\begin{array}{l}0,367 \\
0,133\end{array}$ \\
\hline $\begin{array}{c}\text { Centro-Oeste } \\
\ln Y_{\text {iMulheres }}=\alpha+\beta(t) \\
\ln Y_{\text {iHomens }}=\alpha+\beta(t)\end{array}$ & $\begin{array}{l}3,162 \\
2,251\end{array}$ & $\begin{array}{l}0,002 \\
0,008\end{array}$ & $\begin{array}{l}0,417 \\
1,622\end{array}$ & $\begin{array}{l}0,687 \\
0,139\end{array}$ \\
\hline $\begin{array}{c}\text { Sudeste } \\
\ln Y_{i M u l h e r e s}=\alpha+\beta(t) \\
\ln Y_{i H o m e n s}=\alpha+\beta(t)\end{array}$ & $\begin{array}{l}3,239 \\
2,310\end{array}$ & $\begin{array}{l}0,000 \\
0,008\end{array}$ & $\begin{array}{l}0,072 \\
2,251\end{array}$ & $\begin{array}{l}0,944 \\
0,051\end{array}$ \\
\hline $\begin{array}{c}\text { Sul } \\
\ln Y_{\text {iMulheres }}=\alpha+\beta(t) \\
\ln Y_{\text {iHomens }}=\alpha+\beta(t)\end{array}$ & $\begin{array}{l}3,193 \\
2,232\end{array}$ & $\begin{array}{l}-0,001 \\
0,010\end{array}$ & $\begin{array}{l}-0,206 \\
2,856\end{array}$ & $\begin{array}{l}0,841 \\
0,019\end{array}$ \\
\hline $\begin{array}{c}\text { Brasil } \\
\ln Y_{\text {iMulheres }}=\alpha+\beta(t) \\
\ln Y_{\text {iHomens }}=\alpha+\beta(t)\end{array}$ & $\begin{array}{l}3,228 \\
2,291\end{array}$ & $\begin{array}{l}0,003 \\
0,010\end{array}$ & $\begin{array}{l}0,624 \\
2,782\end{array}$ & $\begin{array}{l}0,548 \\
0,021\end{array}$ \\
\hline
\end{tabular}

Fonte: Elaborado pelos autores

Observando os valores p-fisher para as mulheres e para os homens da Região Norte, verifica-se que o número médio de horas semanais gastas na realização de afazeres domésticos está crescendo mais para os homens (1,6\% a.a.) do que para as mulheres (1,3\% a.a.). Por outro lado, em relação às Regiões Nordeste e Centro-Oeste, não se pode afirmar que haja crescimento nas médias de horas semanais gastas na realização de afazeres domésticos para ambos os sexos (Valores p-fisher > 0,05). Quanto à Região Sudeste, também não se pode afirmar que esteja ocorrendo crescimento ou diminuição na média de horas semanais gastas na realização de afazeres domésticos para as mulheres e para os homens. Contudo, caso o nível de significância fosse flexibilizado para $10 \%(\alpha=0,1)$, poder-se-ia afirmar que o número médio de horas semanais gastas na realização de afazeres domésticos para os homens está crescendo (0,8\% a.a.). Na Região Sul, nota-se que apenas para os homens o número médio de horas semanais gastas na realização de afazeres domésticos está crescendo (1\% a.a.).

$\mathrm{Na}$ análise dos dados em nível nacional, o número médio de horas semanais gastas na realização de afazeres domésticos para as mulheres mostrou-se constante, isto é, durante o período de 11 anos não houve mudança na variável. De modo contrário, para os homens, o número médio de horas semanais gastas na realização de afazeres domésticos está crescendo (1\% a.a.). Ao se considerar o período de 11 anos, pode-se dizer que o número médio de horas 
semanais gastas na realização de afazeres domésticos para os homens cresceu, em média, $11 \%$. Isso revela que os homens, a cada ano, estão participando mais dos afazeres domésticos, podendo essa participação ser um indicador importante de que caminhamos para maior percepção de igualdade entre os sexos no país, e que aquela ideia de "aos homens, a rua; e às mulheres, a casa", não é mais tão regular no cotidiano das famílias da década de 2010.

Percebe-se que a presença masculina na realização de afazeres domésticos apresentou crescimento no Brasil no período analisado (2004-2014), porém, a dedicação ao trabalho doméstico pelos homens ainda se dá em menor proporção em relação às mulheres. De acordo com a literatura de gênero (SOARES, 2008; BRUSCHINI, 2007; RICOLDI, 2010; BRUSCHINI; RICOLDI, 2012; BIDARTE, 2018), ainda que o tempo gasto com a realização de afazeres domésticos pelos homens seja menor que o das mulheres, o envolvimento dos homens no âmbito doméstico não pode ser desprezado, uma vez que eles estão participando mais do cotidiano familiar e dos cuidados com os filhos, e que o comportamento dos indicadores ao longo dos anos investigados mostra-se em processo de crescimento (IBGE, 2015).

Os dados da PNAD ainda são insuficientes para um mapeamento adequado sobre a relação das mulheres e dos homens brasileiros com os afazeres domésticos. No entanto, os resultados desta pesquisa revelam um indicador de mudança de comportamento ou, ainda, de mentalidade da sociedade brasileira, fruto do movimento feminista em prol da igualdade entre os sexos no Brasil. Se a construção do contexto social se deu em séculos e perpetuou por quase todo o tempo a ideia de separação de papéis entre homens e mulheres, pode-se considerar que uma luta começada há seis décadas no país já avançou para desconstruir tudo isso.

\section{CONSIDERAÇÕES FINAIS}

A presente pesquisa buscou analisar a evolução temporal da participação feminina e masculina na realização de afazeres domésticos no Brasil, no período 2004-2014. Constatou-se que no Brasil ainda se perpetua a desigualdade de gênero com relação à distribuição do tempo dedicado à realização de afazeres domésticos, haja vista que as mulheres gastam mais que o dobro de horas semanais na realização de afazeres domésticos do que os homens (25,6 horas para elas, 10,5 horas para eles). Além disso, essa desigualdade também é vista em todas as regiões do país, sendo mais acentuada na Região Nordeste, onde as mulheres gastam 2,52 vezes mais horas semanais na realização de afazeres domésticos do que os homens. Esses dados, de certo modo, eram esperados, considerando o contexto sócio-histórico de construção dos papéis do homem e da mulher na nossa sociedade. No entanto, a análise dos dados em 
nível nacional mostrou que o número médio de horas semanais gastas na realização de afazeres domésticos pelas mulheres manteve-se constante durante o período analisado, mas crescente para os homens (1\% a.a.; $11 \%$ no período analisado). Esse dado, de certa forma, indica que os homens estão participando mais do cotidiano familiar e dos cuidados com os filhos.

Como limitações da pesquisa, menciona-se que os dados referentes às médias de horas semanais gastas na realização de afazeres domésticos, pelas mulheres e pelos homens, total, segundo as regiões do Brasil e em nível nacional, não estão sendo publicados anualmente na Síntese dos Indicadores Sociais pelo IBGE desde 2012. Para se ter acesso aos dados, o pesquisador deve requisitá-los ao Instituto, mediante apresentação de um documento que informe como se dará o uso das informações, podendo a requisição ser negada. Além disso, os dados ainda são incompletos, devido às falhas metodológicas em documentos oficiais, inviabilizando análises mais profundas sobre os mesmos. De certa forma, como destacado por Bruschini (2006, 2007), pode-se dizer que as informações sobre os afazeres domésticos ainda permanecem em poder dos responsáveis pelas pesquisas oficiais nacionais e não permitem à população, de forma geral, acessar esses dados e refletir adequadamente sobre os resultados apresentados.

Os autores posicionam-se junto ao coro de pesquisadores/as sobre o uso do tempo e gênero, em especial, às afirmações de Fontoura e Araújo (2016, p. 19-20), ao esperar que, "por meio dessa leitura, a importância do tema, no Brasil, seja melhor compreendida. É nosso desejo, também, que se amplie o debate, a discussão, a troca de informação e, principalmente, a produção de dados e pesquisas na área. Para se problematizar essas relações de desigualdade entre mulheres e homens, é fundamental que os estudiosos brasileiros tenham acesso a um amplo material para análise". Por fim, incentiva-se que pesquisadores/as desenvolvam estudos aplicando diferentes abordagens teórico-metodológicas sobre o uso do tempo e gênero, coletando informações mais completas e profundas, estimando melhor a carga de trabalho vinculada aos afazeres domésticos e valorando a contribuição dos indivíduos na realização de afazeres domésticos para a economia do país, dentre outros vieses. Ainda, realizar uma discussão sobre os afazeres domésticos, considerando a população em geral e as distinções de gênero que a literatura mais atual aponta, fugindo então dos aspectos público e privado e de homens e mulheres. Isso trará interessantes reflexões e possibilitará discussões sobre as permanências e mudanças das desigualdades entre mulheres e homens na realização de afazeres domésticos no Brasil. 


\section{REFERÊNCIAS}

BIDARTE, M. V. D. "Profissão do lar: imposição ou escolha?" Dissertação (Mestrado) Universidade Federal do Pampa, Mestrado em Administração, 2018.

BIDARTE, M. V. D.; FLECK, C. F.; MELLO, E. M. B. "Para o lar: as mulheres que deixaram o mercado de trabalho para se dedicarem à casa e à família". Revista Gênero, Niterói, v. 19, n. 1, p. 6-24, jul./dez., 2018.

BRUSCHINI, C. Mulher e trabalho: uma avaliação da década da mulher. São Paulo: Nobel, 1985.

BRUSCHINI, C. "Mulher, casa e família”. Revista dos Tribunais, São Paulo, 1990.

BRUSCHINI, C. "O trabalho da mulher brasileira nas décadas recentes". Revista Estudos Feministas, Florianópolis, n. esp., p. 179-199, 1994.

BRUSCHINI, C. "Trabalho doméstico: inatividade econômica ou trabalho não-remunerado?" Revista Brasileira de Estudos de População, São Paulo, v. 23, n. 2, p. 331-353, jul./dez., 2006.

BRUSCHINI, C. "Trabalho e gênero no Brasil nos últimos dez anos". Cadernos de Pesquisa, Fundação Carlos Chagas, São Paulo, v. 37, n. 132, p. 537-572, 2007.

BRUSCHINI, C; RICOLDI, A. M. "Revendo estereótipos: o papel dos homens no trabalho doméstico”. Revista Estudos Feministas, Florianópolis, v. 20, n. 1, p. 259-87, jan./abr., 2012.

COLLIS, J.; HUSSEY, R. Pesquisa em administração: um guia prático para alunos de graduação e pós-graduação. 2. ed. Porto Alegre, Bookman, 2005.

CRESWELL, J. Projeto de pesquisa: métodos qualitativo, quantitativo e misto. 2 ed. Porto Alegre: Artmed, 2007.

DECLARAÇÃo e Plataforma de Ação da IV Conferência Mundial Sobre a Mulher, Pequim, 1995. Disponível em: <http://www.unfpa.org.br/Arquivos/declaracao beijing.pdf >. Acesso em: 10 de dez. de 2016.

FLICK, W. Introdução à pesquisa qualitativa. 3. ed. Porto Alegre: Artmed, 2009.

GUJARATI, D. Econometria básica. 3. ed. São Paulo: Pearson Makron Books, 2000.

INSTITUTO BRASILEIRO DE GEOGRAFIA E ESTATÍSTICA (IBGE). Síntese de indicadores sociais: 2005. Rio de Janeiro: IBGE, 2006a.

IBGE. Síntese de indicadores sociais: 2006. Rio de Janeiro: IBGE, 2006b.

IBGE. Síntese de indicadores sociais: uma análise das condições de vida da população brasileira: 2007. Rio de Janeiro: IBGE, 2007. 
IBGE. Síntese de indicadores sociais: uma análise das condições de vida da população brasileira: 2008. Rio de Janeiro: IBGE, 2008.

IBGE. Síntese de indicadores sociais: uma análise das condições de vida da população brasileira: 2009. Rio de Janeiro: IBGE, 2009.

IBGE. Síntese de indicadores sociais: uma análise das condições de vida da população brasileira: 2010. Rio de Janeiro: IBGE, 2010.

IBGE. Síntese de indicadores sociais: uma análise das condições de vida da população brasileira: 2012. Rio de Janeiro: IBGE, 2012.

IBGE. Síntese de indicadores sociais: uma análise das condições de vida da população brasileira: 2013. Rio de Janeiro: IBGE, 2013.

IBGE. Síntese de indicadores sociais: uma análise das condições de vida da população brasileira: 2014. Rio de Janeiro: IBGE, 2014.

IBGE. Síntese de indicadores sociais: uma análise das condições de vida da população brasileira: 2015. Rio de Janeiro: IBGE, 2015.

MADALOZZO, R.; MARTINS, S.; SHIRATORI, L. "Participação no mercado de trabalho e no mercado doméstico: homens e mulheres têm condições iguais?", Revista Estudos Feministas, Florianópolis, v. 18, n. 2, p. 547-566, 2010.

MELO, H.; CONSIDERA, C.; SABBATO, A. "Os afazeres domésticos contam.", Economia e Sociedade, Campinas, v. 16, n. 3, p. 435-454, dez., 2007.

MELO, H.; CASTILHO, M. “Trabalho reprodutivo no Brasil: Quem faz?”, Revista Economia Contemporânea, Rio de Janeiro, v. 13, n. 1, p. 135-158, jan./abr., 2009.

MELO, H.; SABBATO, A. "Trabalhadoras domésticas: eterna ocupação feminina. Até quando?" In: BARSTED, L.; PITANGUY, J. (Orgs.). O Progresso das Mulheres no Brasil 2003-2010. Rio de Janeiro: CEPia; Brasília: ONU Mulheres, 2011. Cap. 8, p. 179-185.

PERROT, M. Os excluídos da história: operários, mulheres, prisioneiros. Rio de Janeiro, Paz e Terra, 1988.

PESQUISA NACIONAL POR AMOSTRA DE DOMICÍLIOS (PNAD). PNAD de 1992: questionário da pesquisa básica. Rio de Janeiro: IBGE, 1992.

PNAD. PNAD de 2001: questionário da pesquisa básica. Rio de Janeiro: IBGE, 2001.

PNAD. PNAD de 2007: síntese de indicadores. Rio de Janeiro: IBGE, 2008.

PNAD. PNAD de 2009: síntese de indicadores 2009. Rio de Janeiro: IBGE, 2010.

PNAD. PNAD. Porto Alegre: IBGE, microdados 2012, 2013 e 2014.

RICOLDI, A. "A noção de articulação entre trabalho e família e políticas de apoio". Mercado de Trabalho, IPEA, n. 42, p. 37-43, fev., 2010. 
REPORT of the World Conference of the International Women's Year. Mexico City - 1975. United Nations, New York, 1976. Disponível em:

$<$ http://www.un.org/womenwatch/daw/beijing/otherconferences/Mexico/Mexico\%20conference\% 20report\%20optimized.pdf>. Acesso em: 20 de ago. de 2016.

SAFFIOTI, H. O poder do macho. São Paulo: Moderna, 1987.

SOARES, C.; SABÓIA, A. Tempo, trabalho e afazeres domésticos: um estudo com base nos dados da Pesquisa Nacional por Amostra de Domicílios de 2001 e 2005. (Textos para discussão. Diretoria de pesquisas, n. 21), Rio de Janeiro: IBGE, Coordenação de População e Indicadores Sociais, 2007.

SOARES, C. "A distribuição do tempo dedicado aos afazeres domésticos entre homens e mulheres no âmbito da família". Revista Gênero, Niterói, v. 9, n. 1, p. 9-29, jul./dez., 2008.

SORJ, B. "Trabalho remunerado e trabalho não-remunerado". In: VENTURI, G.; RECAMÁN, M.; OLIVEIRA, S. de (Orgs.). A Mulher brasileira nos espaços público e privado. São Paulo: Editora Fundação Perseu Abramo, 2004. p. 107-119.

SORJ, B. O estigma das feministas. Data de 13 de maio de 2005. Disponível em: $<$ http://www.clam.org.br/uploads/conteudo/o estigma das feministas.pdf $>$. Acesso em: 01 de ago. de 2016. 